\title{
Brasil - Angola: aproximando-os através de um conto infantil
}

\author{
Brazil - Angola: approaching them through an \\ infantile story
}

\section{Brésil - Angola: une approche à partir des contes pour enfant}

\author{
Nathalia Fernandes SOARES
}

\begin{abstract}
RESUMO
O presente depoimento relata uma experiência de 'Espaço de criação', estágio realizada em uma escola de educação infantil particular da cidade de São Paulo, proposta no curso "Metodologia e Fundamentos da Alfabetização em países de Língua Oficial Portuguesa: uma introdução" no ano de 2008. O espaço consistiu no desenvolvimento de uma atividade baseada em algumas características dos países que fazem parte do "mundo lusófono", a partir da qual procurei trabalhar a idéia da existência de lugares diferentes que possuem certas semelhanças com o nosso país, aproximando os alunos de algumas características da cultura Africana.
\end{abstract} contos infantis.

Palavras-chave: língua portuguesa - educação infantil - Angola contos infantis.

\begin{abstract}
The present testimony tells an experience occurred during period of training carried through in a private school infantile education, in the city of Sao Paulo, proposed in the course "Methodology and Fundamentals of Alphabetization in countries of Portuguese Official Language: an introduction". The action of training consisted in the development of an activity based on some characteristics of the countries that are part of the "Lusophone world", from which I try to work the idea of the existence of different places that possess certain similarities with ours, approaching the pupils of some characteristics of the African culture.
\end{abstract}


Index terms: Portuguese language - infantile education - Angola infantile stories.

\section{RÉSUMÉ}

Ce témoignage décrit une expérience de 'espace de création' dans une école maternelle de la ville de São Paulo. Cet espace a été proposé au cours "Metodologia e Fundamentos da Alfabetização em países de Língua Oficial Portuguesa: uma introdução" pendant l'anné 2008. L'espace s'est basé sur le développement d'une activité fondée sur les caractéristiques des pays qui font partie du monde lusophone. Il travaille l'idée de l'existence de lieux différent, qui ont des similitudes avec nôtre pays et de rapprochemment avec certaines fonctions de la culture africaine.

Mots clés: langue portugaise, éducation pour enfants, Angola, contes pour enfant.

\section{Depoimento}

A fim de atender a proposta do "espaço de criação" do qual participei no primeiro semestre de 2008, desenvolvi, junto com outras duas participantes, colegas da Faculdade de Educação da Universidade de São Paulo (USP), um projeto de transposição didática a partir do tema central das aulas (alfabetização nos países lusófonos). Tal espaço foi realizado em escolas de educação infantil.

Optamos por utilizar um texto da literatura infantil angolana e, a partir dele, conversar sobre outros países, destacando as diferenças e semelhanças existentes com o nosso país, e também aproximá-las de algumas características da cultura Africana.

Realizei a proposta com alunos de quatro anos de idade em uma escola particular de educação infantil na cidade de São Paulo.

Por não conhecer as crianças com as quais estava trabalhando, iniciei a conversa me apresentando e também perguntando o nome de cada uma. Encontrei uma certa dificuldade em trazer para a sala de aula o assunto da atividade, pois as crianças queriam falar sobre diversos temas, 
principalmente àqueles relacionados aos seus brinquedos favoritos e aos programas de televisão aos quais gostam de assistir.

Como as crianças estavam falando das suas atividades, perguntei o que faziam quando estavam na escola e, dentre as respostas dadas, estava a presença das aulas de inglês. Utilizando a fala de um aluno que disse que "as pessoas falam inglês nos Estados Unidos e aqui a gente só fala às vezes", comecei a atividade programada, explicando que existem outros países que também falam a nossa língua portuguesa. Os alunos quiseram saber se era possível chegar a esses países utilizando uma bicicleta ou o carro de seus pais. Expliquei que só conseguimos chegar aos mesmos viajando de navio ou avião.

Junto com o grupo com o qual desenvolvi a referida proposta, decidimos contar aos alunos que uma amiga nossa de Angola nos mandou uma carta com uma história para que contássemos a eles. Tirei, então, o conto "Kibala - O Rei Leão" de um envelope e li aos alunos. O conto fala de um rei leão que é malvado e não gosta de ver os outros animais da floresta felizes, tirando-lhes os alimentos e também o descanso noturno. Um dia, ao tentar atacar uma palanca que estava doente e com os seus filhotes do lado, o rei leão acaba por cair em uma armadilha feita pelos outros animais que pretendiam mostrar ao rei que não estavam felizes com as atitudes que ele tinha. Kibala fica preso por alguns dias, sem comida, sem água e sem a ajuda dos outros animais. Quando um velho cágado volta de suas férias e encontra a floresta diferente, onde todos estão mais felizes, quer saber o que aconteceu e, depois de ouvir os relatos, pergunta aos outros animais porque estão tratando o leão daquela maneira e diz que se não ajudarem o leão a sair daquele buraco estarão sendo ruins assim como ele era. Os animais, então, ajudam o rei a sair do buraco, dão alimento, matam sua sede e ele vai viver em outro lugar longe daquela floresta.

Como o texto traz alguns animais que não são conhecidos em nosso país, procurei algumas imagens e durante a leitura, ao falar desses animais, 
mostrava as fotos. As crianças não estavam muito concentradas no início da história, mas ao mostrar as imagens, tiveram um maior interesse.

Depois da leitura, iniciamos uma conversa sobre o conto em que as crianças disseram o que aconteceu na história e do que mais gostaram. Pedi, então, que fizessem um registro (desenho) a partir do conto e da conversa. Todos os alunos desenharam os animais, a maioria desenhou o rei e a palanca que no conto era o animal doente que o leão tentou atacar e acabou caindo na armadilha. Fizeram também outros registros relacionados à idéia que têm de uma floresta, com peixes, sol, aranha e jacaré.

Ao final da atividade, conclui que esta foi uma intervenção positiva, apesar de alguns problemas que encontrei, como a dificuldade inicial de relacionar-me com crianças e a dinâmica da escola em que o ruído das outras turmas interfere muito nas atividades, atraindo a atenção das crianças para o que está acontecendo nas outras salas. O trabalho com o espaço de criação foi importante porque permitiu às crianças imaginarem outro lugar que também tem crianças que falam a mesma língua que elas, aproximandoos das semelhanças e das respectivas diferenças.

\section{Referências bibliográficas}

ANTUNES, Gabriela (1982). Kibala, o rei leão. Luanda: INALD. 


\section{AUTORA:}

Nathalia Fernandes Soares

Graduanda da Faculdade de Educação da Universidade de São Paulo (FEUSP).

Contato : nathalia.soares@usp.br

\section{Como citar este depoimento:}

SOARES, Nathalia Fernandes. Brasil - Angola: aproximando-os através de um conto infantil. Revista ACOALFAplp: Acolhendo a Alfabetização nos Países de Língua portuguesa, São Paulo, ano 4, n. 8, 2010. Disponível em: <http://www.acoalfaplp.net>. Publicado em: março - setembro de 2010.

Recebido em junho de 2008./ Aprovado em julho de 2008. 